\title{
Pyruvate dehydrogenase E1-beta deficiency
}

INSERM

\section{Source}

INSERM. (1999). Orphanet: an online rare disease and orphan drug data base. Pyruvate dehydrogenase E1-beta deficiency. ORPHA:255138

Pyruvate dehydrogenase E1-beta deficiency is an extremely rare form of pyruvate dehydrogenase deficiency (PDHD, see this term) characterized by severe lactic acidosis, developmental delay and hypotonia. 